\title{
A unified formulation for circle and polygon concrete-filled steel tube columns under axial compression
}

\author{
Min Yu ${ }^{\mathrm{a}}$, Xiaoxiong Zha ${ }^{\mathrm{a},}$, , Jianqiao Ye ${ }^{\mathrm{b}, *}$, Yuting $\mathrm{Li}^{\mathrm{a}}$ \\ a. Shenzhen Graduate School, Harbin Institute of Technology, Shenzhen 518055, China; \\ b. Department of Engineering, Lancaster University, Lancaster, LA1 4YR. UK;
}

\begin{abstract}
Current design practice of concrete-filled steel tube (CFST) columns uses different formulas for different section profiles to predict the axial load bearing capacity. It has always been a challenge and practically important issue for researchers and design engineers who want to find a unified formula that can be used in the design of the columns with various sections, including solid, hollow, circular and polygonal sections. This has been driven by modern design requirements for continuous optimization of structures in terms of not only the use of materials, but also the topology of structural components. This paper extends the authors' previous work [1] on a unified formulation of the axial load bearing capacity for circular hollow and solid CFST columns to, now, including hollow and solid CFST columns with regular polygonal sections. This is done by taking a circular section as a special case of a polygonal one. Finally, a unified formula is proposed for calculating the axial load bearing capacity of solid and hollow CFST columns with either circular or polygonal sections. In addition, laboratory tests on hollow circular and square CFST long columns are reported. These results are useful addition to the very limited open literature on testing these columns, and are also as a part of the validation process of the proposed analytical formulas.
\end{abstract}

Keywords: Concrete-filled steel tube (CFST), hollow and solid section, circular and polygonal section, load bearing capacity

\section{Notations}

$\begin{array}{ll}f_{s c} & \text { combined strength of CFST } \\ \varphi_{s c} & \text { stability factor of CFST } \\ N_{0} & \text { strength bearing capacity of CFST, } N_{0}=f_{s c} A_{s c} \\ N_{u} & \text { load bearing capacity of CFST, } N_{0}=\varphi_{s c} N_{0}=\varphi_{s c} f_{s c} A_{s c} \\ \eta & \text { enhanced confining coefficient } \\ \eta_{c} & \text { enhanced confining coefficient for circular section } \\ \eta_{c, s} & \text { enhanced confining coefficient for circular solid section } \\ A_{s}, A_{c}, A_{k} & \text { area of steel, concrete and hollow, respectively } \\ A_{s c} & \text { area of CFST section, } A_{s c}=A_{s}+A_{c} \\ \Omega & \text { solid ratio, } \Omega=A_{c} /\left(A_{c}+A_{k}\right) \\ \psi & \text { hollow ratio, } \psi=A_{k} /\left(A_{c}+A_{k}\right)=1-\Omega \\ \beta & \text { ratio of steel area, } \beta=A_{s} /\left(A_{s}+A_{c}\right) \\ \alpha & \text { steel ratio, } \alpha=A_{s} / A_{c} \\ \alpha_{s c} & \text { solid steel ratio, } \alpha_{s c}=A_{s} /\left(A_{c}+A_{k}\right) \\ I_{s}, I_{c} & \text { moment of inertia of steel, concrete, respectively } \\ I_{s c} & \text { composite moment of inertia, } I_{s c}=I_{s}+I_{c} \\ f_{c k}, f_{y} & \text { characteristic strength of concrete and steel, respectively }\end{array}$




\begin{tabular}{|c|c|}
\hline$\xi_{s c}$ & solid confining coefficient, $\xi_{s c}=\alpha_{s c} f_{y} / f_{c k}$ \\
\hline$\xi$ & confining coefficient, $\xi=\alpha f_{y} / f_{c k}$ \\
\hline$E_{c}, E_{s}$ & elastic modulus of concrete and steel, respectively \\
\hline $\begin{array}{l}E_{s c} \\
k_{e}\end{array}$ & $\begin{array}{l}\text { composite bending modulus, } E_{s c}=\left(E_{c} I_{c}+E_{s} I_{s}\right) / I_{s c} \\
\text { confinement effectiveness coefficient, } k_{e}=k_{h} k_{n}\end{array}$ \\
\hline$k_{h}$ & hollow confinement effectiveness coefficient \\
\hline$k_{n}$ & polygon confinement effectiveness coefficient \\
\hline$n$ & edge number, for circular cross section, take infinity \\
\hline K & initial imperfection coefficient \\
\hline$K_{c}$ & initial imperfection coefficient for circular CFST \\
\hline$L$ & effective length of column \\
\hline & slenderness ratio, $\lambda=L_{0} / \sqrt{I_{s c} / A_{s c}}$ \\
\hline & non-dimensional slenderness ratio, $\bar{\lambda}_{s c}=\lambda / \pi \cdot \sqrt{ }$ \\
\hline
\end{tabular}

\section{Introduction}

A concrete-filled steel tube (CFST) column is formed by filling a steel tube with concrete. According to the form of the cross-section, CFST columns can be divided into different groups, such as circular, square and octagon CFST columns, etc. The cross sections of these columns can be either solid or hollow. A solid concrete-filled steel tube (S-CFST) column is formed by pouring wet concrete into the entire space enclosed by the steel tube, and a hollow concrete-filled steel tube (H-CFST) one is formed by pouring concrete into a steel tube using the centrifugal method. Figure 1-1 shows some of the commonly used cross sections of the concrete-filled steel tube columns.

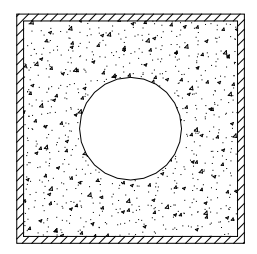

a) Hollow square

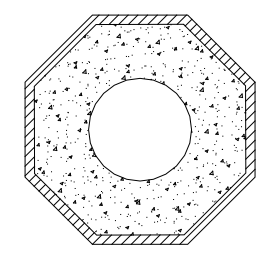

b) Hollow octagonal

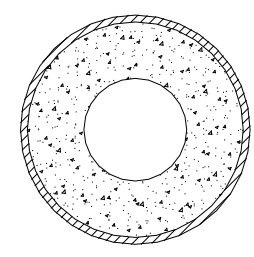

c) Hollow circular

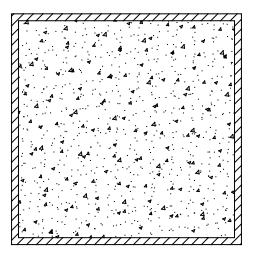

d) Solid square

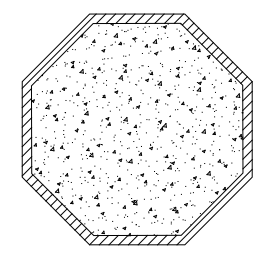

e) Solid octagonal

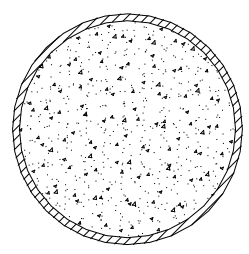

f) Solid circular

Figure 1-1 Common section types of CFSTs

Axial load bearing capacity of a CFST column is an important and fundamental design parameter in construction engineering. Extensive research on solid CFST columns has been conducted either experimentally or analytically. Comprehensive research monographs have been published by Zhong ${ }^{[2]}$, $\mathrm{Han}^{[3]}$, Zhao ${ }^{[4]}$, $\mathrm{Zha}^{[5]}$ and Chiaki ${ }^{[6]}$. There are also many published research papers on experimental studies of solid circular ${ }^{[7-9]}$, elliptical $^{[10]}$, octagonal ${ }^{[11-13]}$ and square CFST ${ }^{[14-18]}$ columns. Numerical simulations also played an important role in studying the behavior of solid CFST columns under axial compression ${ }^{[19-22]}$ and eccentric loading ${ }^{[23-24]}$. Practical design formulas were proposed and adopted in, for example, CECS 254:2009 ${ }^{[25]}$ for hollow, Eurocode $4^{[26]}$ for solid and $\operatorname{Han}^{[3]}$ for circular and square solid CFST columns.

From the above, it can be concluded that most of the research in the last few decades focused only on solid CFST columns. Different design formulas and procedures were recommended for columns with different section profiles. This is not ideal for modern structural design where structural, material, architectural, aesthetic and environmental parameters are all designed in a continuous manner to achieve the best possible design. The modern procedure requires a continuous change of all design parameters, including section 
profiles of the CFST columns. It is obvious that a unified formulation for the calculation of axial load bearing capacity of CFST columns with various section profiles will benefit both analytically and computationally the overall design process. Fortunately, obtaining a unified design solution for all the sections shown in Fig. 1 is possible since (a) materially, the difference between a solid and a hollow section is the hollow ratio and a solid section can be viewed as a special hollow section with a hollow ratio of zero; and (b) geometrically, the difference between a circular and a regular polygonal section is the number of sides and a circular section can be viewed as a special polygonal section with an infinite number of sides.

On the basis of the aforementioned special cases, this paper attempts to extend the axial load bearing capacity formula of a circular CFST column to the columns with polygonal sections, and a unified formula is finally obtained for both hollow and solid circular and polygonal sections.

\section{Unified formulation of the strength for circle and polygon CFST columns}

\subsection{Simplification of the unified formula for circular sections}

A unified formula for both solid and hollow sections was proposed in reference [1] to predict the strength of a CFST column through decomposition of the elastic deformation of a circular concrete filled steel tube into a uniaxial compression and a plane strain problem. Displacement compatibility and the solution of thick-walled cylinder were then introduced to derive the strength formula that is applicable for both solid and hollow circular sections. The formula was validated by experimental results, and is shown below ${ }^{[1]}$ :

$$
f_{s c}=\left(1+\eta_{c}\right)\left[(1-\beta) f_{c k}+\beta f_{y}\right]
$$

in which

$$
\eta_{c}=\frac{\Omega \xi_{s c}}{\left[2.0 \Omega+0.05 \xi_{s c}+\left(0.2 \frac{f_{c k}}{f_{y}}-0.05\right) \xi_{s c} \Omega\right]\left(\Omega+\xi_{s c}\right)}
$$

where, $\eta_{c}$ is the enhanced confining coefficient for circular section; $\beta$ is the ratio of steel area; $\Omega$ is the solid ratio; and $\xi_{s c}$ is the solid confining coefficient. The definitions of all the symbols are list in the Notations.

From the definitions of the confining coefficient $\xi$, solid ratio $\Omega$ and solid confining coefficient $\xi_{\text {sc }}$, one has

$$
\xi_{s c}=\Omega \xi
$$

Inserting Eq.(2-2) into Eq. (2-1b) yields:

$$
\eta_{c}=k \times 0.5 \frac{\xi}{1+\xi}
$$

where

$$
k=\frac{2}{2+0.2 \alpha_{s c}+0.05 \alpha_{s c} \frac{f_{y}}{f_{c k}}\left(\frac{1}{\Omega}-1\right)}
$$

In engineering practice, the most commonly used steel varies from Q235 to Q420, and the concrete grade from C.30 to C.80. The values of $f / f$, therefore. is somewhere hetween 4.7 and 20.9 .

For solid CFST columns, the steel ratio $\alpha_{s c}$ is between 0.04 and 0.2 , and $\Omega=1$. Approximately, the enhanced confining coefficient for a solid circular section is then:

$$
\eta_{c, s}=\frac{2}{2+0.2 \alpha_{s c}} \times 0.5 \frac{\xi}{1+\xi} \approx 0.5 \frac{\xi}{1+\xi}
$$

The relationship between the coefficient $k$ and the solid ratio $\Omega$ in Eq.(2-3b) is shown by Figure 2-1. 


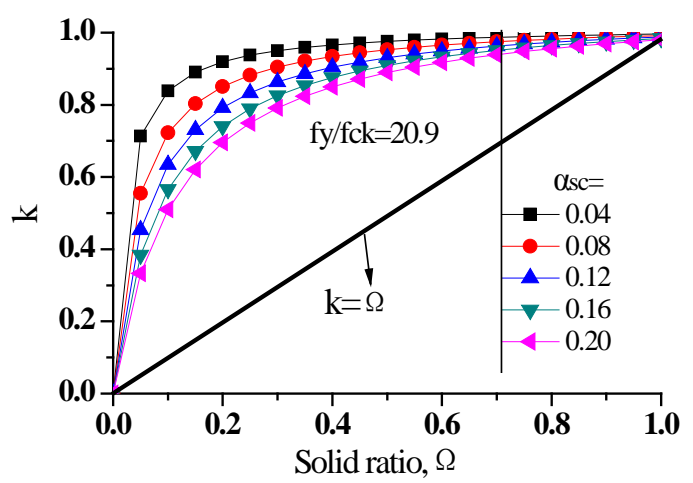

a) $f_{y} / f_{c k}=20.9$

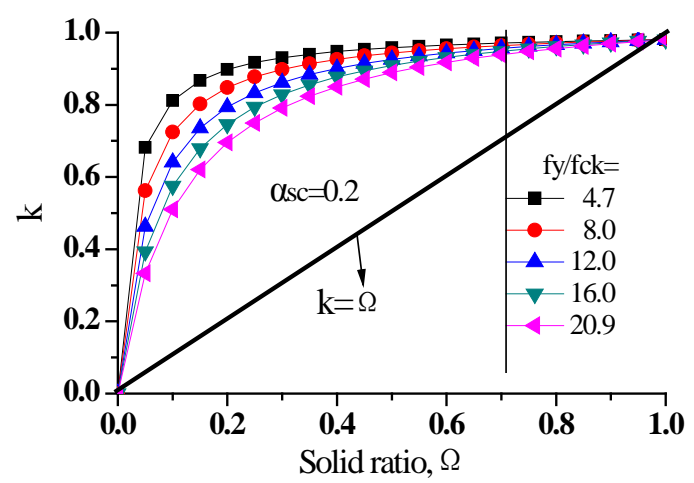

b) $\alpha_{s c}=0.2$

Figure 2-1 The relationship between coefficient $k$ and solid ratio $\Omega$

Further numerical tests show that, for any combination of the parameters, $k$ is always smaller than $\Omega$. Thus, by assuming,

$$
k=\Omega=1-\psi
$$

a simplified Eq.(2-3) can be obtained, which leads always to a conservative design. It will be seen later that this approximation does not affect significantly the accuracy of the predictions.

Eq. (2-3a) now becomes:

$$
\eta_{c}=0.5 \frac{\xi}{1+\xi} \Omega=\Omega \times \eta_{c, s}
$$

The strength and the axial load bearing capacity of a circular CFST column are, respectively:

and

$$
f_{s c}=\frac{1+(1+0.5 \Omega) \xi}{1+\alpha} f_{c k}
$$

where, $\alpha$ is the steel ratio .

\subsection{Extension of the strength formula to polygon sections}

For a CFST column with a polygonal cross section, the common practice in design is to find the solution of a column with an equivalent circular section. The solution is then modified by a correction factor. The correction factor is usually considered in the confining coefficient ${ }^{[25]}$. Research also showed that the confinement of a square steel tube on the concrete can be divided into an effective enhanced zone and non-enhanced zone ${ }^{[27]}$, separated by boundaries of parabolic shape. Similarly, assuming that the same principle applies to a regular polygonal section and, with the increase of the number of sides, the effective enhanced zone approaches that of a circular section.

Based on the effective area method, Mander ${ }^{[28]}$ proposed a constitutive model for concrete reinforced with stirrups by using an equivalent model of uniform constraint. Following this approach, the non-uniform confinement pressure on the concrete from a polygonal steel tube can be equivalent to a uniform confinement pressure from a circular steel tube, i.e.:

$$
P^{\prime}=k_{e} P
$$

where. $P^{\prime}$ is the effective confining nressure: $P$ is the confining nressure from a circular steel tube, and is uniformly distributed; ${ }^{k}$ is the confinement effectiveness coefficient.

Eq.(2-8) is valid for columns with solid sections. For a column with a hollow section, a similar approach 
is followed to calculate the effective confining pressure. This approach has two steps as shown in Figure 2-2.

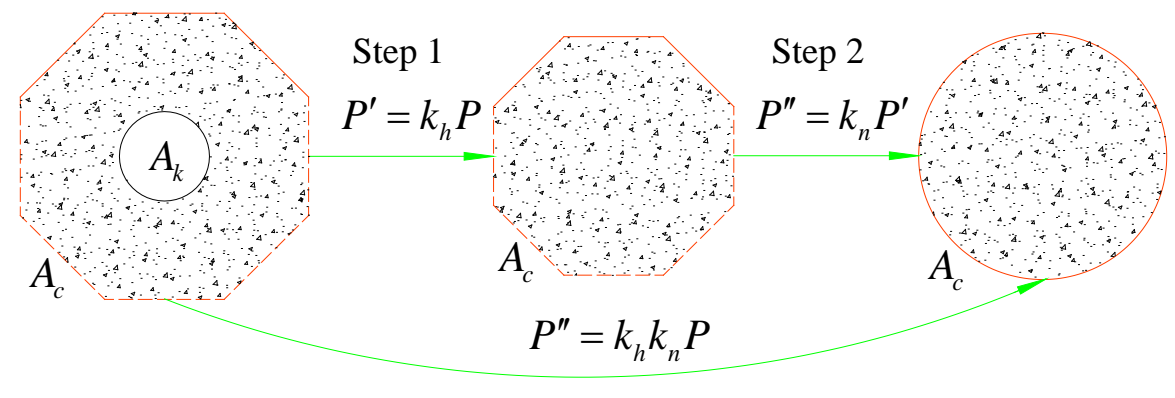
(a) Hollow polygonal section
(b) Solid polygonal section
(c) Solid circular section

Figure2-2 Equivalent hollow and polygonal sections

The first step finds an equivalent solid section (b) of the hollow one (a). Both have the same form of the external boundary and the same cross sectional area. Thus, a correction factor, $k_{h}$ is introduced between (a) and (b). The second step finds a solid circular section (c) that has the same cross sectional area as the polygonal section (b), and hence introduces another correction factor $k_{n}$. In the following sections, the two correction factors are also defined as their respective effectiveness coefficients.

By following these steps, the non-uniform confining pressure of a hollow polygonal section can be equivalent to a uniform confining pressure on an equivalent circular solid section, i.e.:

$$
P^{\prime \prime}=k_{e} P=k_{h} k_{n} P
$$

where, $P^{\prime \prime}$ _ effective confining pressure;

$P$ _ confining nressure from the steel tuhe;

$k_{e}$ __onfinement effectiveness roefficient:

$k_{h}$ __ hollow confinement effectiveness coefficient:

$k_{n} \_$polygon confinement effectiveness coefficient.

Eq.(2-8) proposes an equivalent system that requires introduction of an effectiveness coefficient that accounts for the effect of the hollow and polygonal section profile on the confining pressure. Similar to the solution proposed in [1] for circular sections, a formula for a polygonal section can be obtained in the following form:

$$
f_{s c}=\left(1+k_{e} \eta_{c, s}\right)\left[(1-\beta) f_{c k}+\beta f_{y}\right]
$$

The overall confining coefficient is now the confining coefficient of the solid section, $\eta_{c, s}$, multiplied by the effectiveness coefficient $k_{e}$. Therefore, the enhanced confining coefficient for both a circular and a polygonal section can be generally written as:

$$
\eta=k_{e} \eta_{c, s}=k_{h} k_{n} \eta_{c, s}=k_{h} k_{n} \times 0.5 \frac{\xi}{1+\xi}
$$

For a circular section, $k_{n}=1$. Hence:

$$
\eta_{c}=k_{h} \times 0.5 \frac{\xi}{1+\xi}
$$

From Eq.(2-6) and Eq.(2-11), the confinement effectiveness coefficient, $k_{h}$,of a hollow section can be 
obtained by dividing the solid area $A_{c}$ with the sum of the solid and hollow areas $A_{c}+A_{k}$ :

$$
k_{h}=\Omega=\frac{A_{c}}{A_{c}+A_{k}}
$$

For a polygonal solid section, $k_{n}$ is obtained by dividing the area of the effective enhanced zone $A_{e}$ with the total area of concrete $A_{c}{ }^{[28]}$ of the solid section, i.e.,

$$
k_{n}=\frac{A_{e}}{A_{c}}
$$

It can be seen from the above that it is essential to define the boundary between the effective enhanced and the non-enhanced zones as shown in Figure 2-3. Mander ${ }^{[28]}$ assumed that the boundary between the two zones is a parabola, with an angle of 45 degrees at the intersection of the tangent of the boundary and the side of the polygon, as shown in Figure 2-3.

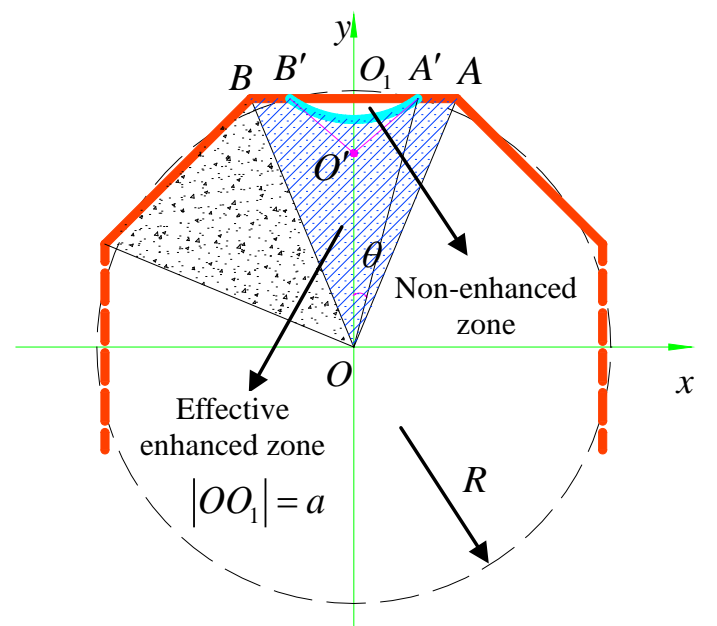

Parameter description:

1. $A B$ is a side of the polygon, and $O_{1}$ is the middle point of the side;

2. $\angle A^{\prime} B^{\prime} O^{\prime}=\angle B^{\prime} A^{\prime} O^{\prime}=45^{\circ}$;

3. $R$ is the radius of the equivalent circle of the polygon having the same area. $r$ is the radius of the hollow. $a$ is the radius of incircle of the polygon;

4. $\angle A^{\prime} O O_{1}=\theta$.

Figure 2-3 Effective enhanced zone

In Figure 2-3, the coordinates of point $\mathrm{A}$ is $(a \tan \alpha, a)$, where $\alpha=\pi / n$ and $n$ is the number of sides. The non-enhanced area related to side $A B$, which is the area enclosed by the side and the parabola, is $A_{\text {non }}=2 / 3 a^{2} \tan ^{2} \theta$. The area of concrete is $A_{c}=n a^{2} \tan \alpha$. For the entire section, therefore, the effectiveness coefficient is

$$
k_{n}=\frac{A_{c}-n \times A_{\text {non }}}{A_{c}}=1-\frac{2}{3} \frac{\tan ^{2} \theta}{\tan \alpha}
$$

It is clear from Eq.(2-14) that the effectiveness coefficient depends solely on the positions of $A^{\prime}$ and $B^{\prime}$. i.e, how the equivalent circular sections are defined. Two cases are considered in this paper:

Case 1: The area of the equivalent circular section is the same as that of the polygonal section. In this case the circular boundary has two intersections with each side of the polygon. The effectiveness coefficient of this case is calculated below.

Since the equal cross sectional areas: $n a^{2} \tan \alpha=\pi R^{2}$,

Thus, $\frac{a^{2}}{R^{2}}=\frac{\pi}{n} \frac{1}{\tan \alpha}=\frac{\alpha}{\tan \alpha}$,

From Figure 2-3, $\cos \theta=\frac{a}{R}$,

Thus, $\frac{\alpha}{\tan \alpha}=\cos ^{2} \theta$, and then $\tan ^{2} \theta=\frac{\tan \alpha}{\alpha}-1$. 
Substituting the above into Eq.(2-14) yields

$$
k_{n}=1-\frac{2}{3}\left(\frac{1}{\alpha}-\frac{1}{\tan \alpha}\right), \alpha=\frac{\pi}{n}
$$

Case 2: The equivalent circular section is taken as the circumcircle of the polygon. In this case the circle passes through all the vertices of the polygon, i.e., $A^{\prime}$ and $B^{\prime}$ coincide, respectively, with $\mathrm{A}$ and $\mathrm{B}$. Thus, $\theta=\alpha$, and Eq.(2-14) is reduced to:

$$
k_{n}=1-\frac{2}{3} \tan \alpha, \alpha=\frac{\pi}{n}
$$

From Eqs. (2-15) and (2-16), it can be seen that the correction coefficient $k_{e}$ is a function of the number of sides and the hollow ratio. When the number of sides approaches infinity, $k_{e}$ approaches unity for a circular section. The $k_{n}$ of the two cases for different number of sides are shown in Figure 2-4, where the curves of cases 1 and 2 were obtained from Eqs.(2-15) and (2-16), respectively. The curve of the simplified formula was plotted by using the following approximate equation:

$$
k_{n}=\frac{n^{2}-4}{n^{2}+20}
$$

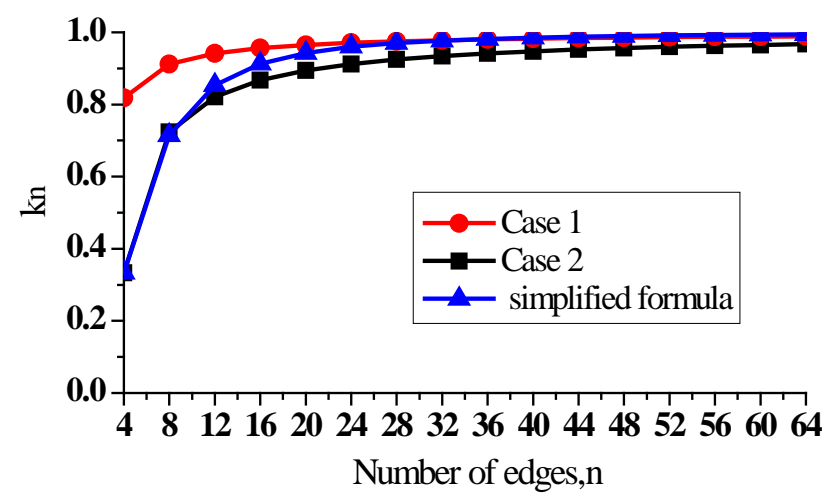

Figure 2-4 $k_{n}$ vs. $n$ curves for the two cases

Eq. (2-17) is formed from a regression analysis on the results of the two cases by considering the facts that: (a) when the number of sides is greater than 16, Figure 2-4 shows that $k_{n}$ is close to 1 , and (b) when the number is smaller than 8, Case 2 provides a safer design. It is evidence that Eq.(2-17) is simple and links $k_{n}$ directly to the number of sides of a polygon. The equation can be used in design in a straightforward manner.

Thus, the unified combined strength formula and the axial load bearing capacity of a general polygonal CFST column are, respectively:

and

$$
f_{s c}=\frac{1+\left(1+0.5 k_{e}\right) \xi}{1+\alpha} f_{c k}
$$

where:

$\xi-$ confining coefficient, $\xi=A_{s} f_{y} / A_{c} f_{c k} ;$

$f_{y}, f_{c k}$ characteristic strength values for steel and concrete respectively;

$A_{s}, A_{c}, A_{k} \longrightarrow$ area of steel, concrete and hollow, respectively;

$k_{e}$ Confinement effectiveness coefficient, $k_{e}=k_{h} k_{n}$;

$k_{h} \_$hollow confinement effectiveness coefficient, $k_{h}=\Omega=1-\psi$; 
$k_{n}$ polygon confinement effectiveness coefficient, $k_{n}=\left(n^{2}-4\right) /\left(n^{2}+20\right), n$ is the side number.

These unified formulas apply to all forms of solid and hollow sections of concrete filled steel tube columns. For a solid circular CFST column, $k_{h}=k_{n}=1$, and for other section profiles, the column strengths are obtained from their respective equivalent solid circular CFST ones.

\subsection{Verification of the unified strength formula for CFST columns under uniaxial compression}

To verify the unified strength formula, the circular CFST columns investigated in Tables 1 and 2 of [1] were studied here first using Eq.(2-18). The predicted axial load bearing capacity was compared with the experimental results. The comparisons, which are not presented here, showed that the average ratios of $N_{0} / N_{\text {test }}$ were 0.963 and 1.055 , with a variance of 0.016 and 0.007 , respectively. This demonstrates that the unified formula can provide good predictions to the strength of circular CFST columns.

After this successful validation for circular CFST columns, the unified strength formula was used to predict the axial load bearing capacity of octagonal and square CFST short columns under uniaxial compression. New experimental tests on short columns were also carried out for validations. The comparisons are presented in Table 2-1 and Table 2-2. It is evident that the predicted load bearing capacity agrees very well with the test results for all the cases. The average ratios of $N_{0} / N_{\text {test }}$, are 0.987 and 0.957 , and the variance are 0.012 and 0.006 , respectively, for the octagonal hollow and solid columns. For the square columns, the respective average ratios $N_{0} / N_{\text {test }}$ of the hollow and solid sections are 1.066 and 0.940 , and the variance are 0.014 and 0.007. From these results, it appears that the number of sides of the sections does not have significant influence on the accuracy of the predictions. It is noticed that the predicted load bearing capacity can be either greater or smaller than the tested values, which should be aware of when the formula is used in design.

Table 2-1 Comparison of formula based and experimental results for octagonal hollow and solid CFST

\begin{tabular}{|c|c|c|c|c|c|c|c|c|c|c|c|c|}
\hline \multirow{3}{*}{ Type } & \multirow{3}{*}{ Ref. } & \multicolumn{2}{|c|}{$\begin{array}{l}\text { Explanation of } \\
\text { numbering }\end{array}$} & \multicolumn{3}{|c|}{ Geometric parameters } & \multicolumn{3}{|c|}{ Material } & \multirow{3}{*}{$\begin{array}{c}\text { Tests } \\
\text { Ntest } \\
\text { /KN }\end{array}$} & \multirow{3}{*}{$\begin{array}{l}\text { Cal. } \\
\text { N0 } \\
\text { /kN }\end{array}$} & \multirow{3}{*}{$\begin{array}{c}\text { Ratio } \\
\text { N0/Ntest }\end{array}$} \\
\hline & & \multirow{2}{*}{ NO. } & \multirow{2}{*}{ Numbering } & $\begin{array}{l}\text { Length } \\
\text { of side }\end{array}$ & $\begin{array}{c}\text { Steel } \\
\text { thickness }\end{array}$ & $\begin{array}{l}\text { Radius } \\
\text { of hollow }\end{array}$ & \multirow{2}{*}{$\begin{array}{c}\text { fy } \\
\text { /Mpa }\end{array}$} & \multirow{2}{*}{$\begin{array}{c}\mathrm{f}^{\prime} \mathrm{c} \\
/ \mathrm{Mpa}\end{array}$} & \multirow{2}{*}{$\begin{array}{c}\text { fck } \\
\text { /Mpa }\end{array}$} & & & \\
\hline & & & & $\mathrm{B} / \mathrm{mm}$ & $\mathrm{t} / \mathrm{mm}$ & $\mathrm{rco} / \mathrm{mm}$ & & & & & & \\
\hline \multirow{9}{*}{$\begin{array}{c}\text { octagonal } \\
\text { hollow } \\
\text { CFST }\end{array}$} & \multirow{9}{*}{ [2] } & 1 & $1 \mathrm{C}-1$ & 118.9 & 2.50 & 111.5 & 334.6 & & 40.50 & 2100.0 & 1990.0 & 0.948 \\
\hline & & 2 & $1 \mathrm{C}-2$ & 118.9 & 2.50 & 111.5 & 334.6 & & 40.50 & 1830.0 & 1990.0 & 1.087 \\
\hline & & 3 & 2C-1 & 118.6 & 3.00 & 100.5 & 317.3 & & 40.50 & 2160.0 & 2407.7 & 1.115 \\
\hline & & 4 & $2 \mathrm{C}-2$ & 118.6 & 3.00 & 100.1 & 317.3 & & 40.50 & 2250.0 & 2420.6 & 1.076 \\
\hline & & 5 & 3C-1 & 118.1 & 3.80 & 99.5 & 315.0 & & 40.50 & 2580.0 & 2643.1 & 1.024 \\
\hline & & 6 & $3 C-2$ & 118.1 & 3.80 & 99.2 & 315.0 & & 40.50 & 2770.0 & 2653.3 & 0.958 \\
\hline & & 7 & $5 \mathrm{C}-1$ & 117.6 & 4.75 & 99.0 & 315.8 & & 46.00 & 2900.0 & 3090.2 & 1.066 \\
\hline & & 8 & $6 C-1$ & 117.6 & 4.75 & 98.8 & 315.8 & & 28.40 & 3200.0 & 2539.8 & 0.794 \\
\hline & & 9 & $6 C-2$ & 117.6 & 4.75 & 100.2 & 315.8 & & 28.40 & 3080.0 & 2506.9 & 0.814 \\
\hline \multirow{6}{*}{$\begin{array}{c}\text { octagonal } \\
\text { solid } \\
\text { CFST }\end{array}$} & \multirow{3}{*}{ [5] } & 10 & CFST-1 & 80.0 & 5.00 & 0.0 & 295.8 & & 24.51 & 1916.0 & 1930.2 & 1.007 \\
\hline & & 11 & CFST-2 & 80.0 & 5.00 & 0.0 & 295.8 & & 24.51 & 1907.0 & 1930.2 & 1.012 \\
\hline & & 12 & CFST-3 & 80.0 & 5.00 & 0.0 & 295.8 & & 24.51 & 1906.0 & 1930.2 & 1.013 \\
\hline & \multirow{3}{*}{ [11] } & 13 & $8-1 \mathrm{P}$ & 120.0 & 1.18 & 0.0 & 231.3 & & 36.35 & 3200.0 & 2839.9 & 0.887 \\
\hline & & 14 & $8-1 G$ & 120.0 & 1.18 & 0.0 & 231.3 & & 49.12 & 4350.0 & 3713.4 & 0.854 \\
\hline & & 15 & $8-2 \mathrm{P}$ & 100.0 & 0.97 & 0.0 & 231.3 & & 36.35 & 2313.0 & 1969.2 & 0.851 \\
\hline
\end{tabular}




\begin{tabular}{|c|c|c|c|c|c|c|c|c|c|c|c|}
\hline & 16 & 8-3P & 90.0 & 1.00 & 0.0 & 231.3 & & 36.35 & 1799.0 & 1620.2 & 0.901 \\
\hline & 17 & $8-4 \mathrm{P}$ & 80.0 & 1.06 & 0.0 & 231.3 & & 36.35 & 1525.0 & 1310.2 & 0.859 \\
\hline & 18 & $8-4 G$ & 80.0 & 1.06 & 0.0 & 231.3 & & 49.12 & 2043.0 & 1696.2 & 0.830 \\
\hline \multirow{9}{*}{ [12] } & 19 & $2 \mathrm{HN}$ & 62.1 & 2.0 & 0.0 & 341.3 & 30.1 & 25.5 & 1003.0 & 903.5 & 0.901 \\
\hline & 20 & $3 \mathrm{HN}$ & 62.1 & 3.2 & 0.0 & 300.2 & 30.1 & 25.5 & 1100.0 & 1068.4 & 0.971 \\
\hline & 21 & $4 \mathrm{HN}$ & 62.1 & 4.0 & 0.0 & 294.3 & 30.1 & 25.5 & 1273.0 & 1197.3 & 0.941 \\
\hline & 22 & $2 \mathrm{MN}$ & 62.1 & 2.0 & 0.0 & 341.3 & 21.9 & 18.5 & 782.0 & 781.0 & 0.999 \\
\hline & 23 & $3 \mathrm{MN}$ & 62.1 & 3.2 & 0.0 & 300.2 & 21.9 & 18.5 & 946.0 & 949.8 & 1.004 \\
\hline & 24 & $4 \mathrm{MN}$ & 62.1 & 4.0 & 0.0 & 294.3 & 21.9 & 18.5 & 1108.0 & 1081.3 & 0.976 \\
\hline & 25 & $2 \mathrm{LN}$ & 62.1 & 2.0 & 0.0 & 341.3 & 16.7 & 14.1 & 650.0 & 703.2 & 1.082 \\
\hline & 26 & 3LN & 62.1 & 3.2 & 0.0 & 300.2 & 16.7 & 14.1 & 803.0 & 874.6 & 1.089 \\
\hline & 27 & $4 \mathrm{LN}$ & 62.1 & 4.0 & 0.0 & 294.3 & 16.7 & 14.1 & 968.0 & 1007.8 & 1.041 \\
\hline
\end{tabular}

Table 2-2 Comparison of formula based and experimental results for square hollow and solid CFST

\begin{tabular}{|c|c|c|c|c|c|c|c|c|c|c|c|c|}
\hline \multirow{3}{*}{ Type } & \multirow{3}{*}{ Ref. } & \multicolumn{2}{|r|}{ Serial } & \multicolumn{3}{|c|}{ Geometric parameters } & \multicolumn{3}{|c|}{ Material } & \multirow{3}{*}{$\begin{array}{c}\text { Tests } \\
\text { Ntest } \\
\text { /KN }\end{array}$} & \multirow{3}{*}{$\begin{array}{l}\text { Cal. } \\
\text { N0 } \\
/ \mathrm{kN}\end{array}$} & \multirow{3}{*}{$\begin{array}{c}\text { Ratio } \\
\text { N0/Ntest }\end{array}$} \\
\hline & & \multirow[t]{2}{*}{ NC. } & \multirow{2}{*}{ Numbering } & \multirow{2}{*}{\begin{tabular}{|c|} 
Length of side \\
$\mathrm{B} / \mathrm{mm}$
\end{tabular}} & \multirow{2}{*}{$\begin{array}{c}\text { Thickness } \\
\text { t/mm }\end{array}$} & \multirow{2}{*}{$\begin{array}{c}\begin{array}{c}\text { Radius } \\
\text { of hollow }\end{array} \\
\text { rco/mm }\end{array}$} & \multirow{2}{*}{$\begin{array}{c}\text { fy } \\
/ \mathrm{Mpa}\end{array}$} & \multirow{2}{*}{$\begin{array}{l}\mathrm{f}^{\prime} \mathrm{c} \\
/ \mathrm{Mpa}\end{array}$} & \multirow{2}{*}{$\begin{array}{l}\text { fck } \\
\text { /Mpa }\end{array}$} & & & \\
\hline & & & & & & & & & & & & \\
\hline \multirow{9}{*}{$\begin{array}{l}\text { square } \\
\text { Hollow } \\
\text { CFST }\end{array}$} & \multirow{9}{*}{ [2] } & 1 & $1 \mathrm{D}-1$ & 238.0 & 2.50 & 93.7 & 334.6 & & 40.5 & 1700.0 & 1935 & 1.14 \\
\hline & & 2 & $1 \mathrm{D}-2$ & 238.0 & 2.50 & 93.0 & 334.6 & & 40.5 & 1900.0 & 1952 & 1.03 \\
\hline & & 3 & 2D-1 & 237.4 & 3.00 & 81.0 & 317.3 & & 40.5 & 1990.0 & 2318 & 1.16 \\
\hline & & 4 & 2D-2 & 237.4 & 3.00 & 81.4 & 317.3 & & 40.5 & 2400.0 & 2310 & 0.96 \\
\hline & & 5 & 3D-1 & 237.1 & 3.80 & 80.0 & 315.0 & & 40.5 & 2190.0 & 2551 & 1.16 \\
\hline & & 6 & 5D-1 & 237.8 & 4.75 & 79.2 & 315.8 & & 46.0 & 2990.0 & 3036 & 1.02 \\
\hline & & 7 & $5 \mathrm{D}-2$ & 237.8 & 4.75 & 79.0 & 315.8 & & 46.0 & 2420.0 & 3039 & 1.26 \\
\hline & & 8 & $6 \mathrm{D}-1$ & 237.3 & 4.75 & 80.0 & 315.8 & & 28.4 & 2880.0 & 2441 & 0.85 \\
\hline & & 9 & $6 \mathrm{D}-2$ & 237.3 & 4.75 & 79.9 & 315.8 & & 28.4 & 2400.0 & 2443 & 1.02 \\
\hline \multirow{23}{*}{$\begin{array}{l}\text { square } \\
\text { Solid } \\
\text { CFST }\end{array}$} & \multirow{8}{*}{ [14] } & 10 & R1-1 & 120.0 & 4.00 & 0.0 & 495.0 & 60.0 & 47.9 & 1701.0 & 1673 & 0.98 \\
\hline & & 11 & R1-2 & 120.0 & 4.00 & 0.0 & 495.0 & 60.0 & 47.9 & 1657.0 & 1673 & 1.01 \\
\hline & & 12 & R4-1 & 130.0 & 4.00 & 0.0 & 495.0 & 60.0 & 47.9 & 2020.0 & 1878 & 0.93 \\
\hline & & 13 & R4-2 & 130.0 & 4.00 & 0.0 & 495.0 & 89.0 & 70.7 & 2018.0 & 2217 & 1.10 \\
\hline & & 14 & R7-1 & 106.0 & 4.00 & 0.0 & 495.0 & 89.0 & 70.7 & 1749.0 & 1622 & 0.93 \\
\hline & & 15 & R7-2 & 106.0 & 4.00 & 0.0 & 495.0 & 89.0 & 70.7 & 1824.0 & 1622 & 0.89 \\
\hline & & 16 & R10-1 & 140.0 & 4.00 & 0.0 & 495.0 & 89.0 & 70.7 & 2752.0 & 2489 & 0.90 \\
\hline & & 17 & R10-2 & 140.0 & 4.00 & 0.0 & 495.0 & 89.0 & 70.7 & 2828.0 & 2489 & 0.88 \\
\hline & \multirow{8}{*}{ [15] } & 18 & A1 & 120.0 & 5.80 & 0.0 & 300.0 & 83.0 & 66.0 & 1697.0 & 1702 & 1.00 \\
\hline & & 19 & $\mathrm{~A} 2$ & 120.0 & 5.80 & 0.0 & 300.0 & 106.0 & 84.2 & 1919.0 & 1917 & 1.00 \\
\hline & & 20 & A3-1 & 200.0 & 5.80 & 0.0 & 300.0 & 83.0 & 66.0 & 3996.0 & 3918 & 0.98 \\
\hline & & 21 & A3-2 & 200.0 & 5.80 & 0.0 & 300.0 & 83.0 & 66.0 & 3862.0 & 3918 & 1.01 \\
\hline & & 22 & A9-1 & 120.0 & 4.00 & 0.0 & 495.0 & 55.0 & 44.3 & 1739.0 & 1627 & 0.94 \\
\hline & & 23 & A9-2 & 120.0 & 4.00 & 0.0 & 495.0 & 55.0 & 44.3 & 1718.0 & 1627 & 0.95 \\
\hline & & 24 & A12-1 & 130.0 & 4.00 & 0.0 & 495.0 & 55.0 & 44.3 & 1963.0 & 1823 & 0.93 \\
\hline & & 25 & A12-2 & 130.0 & 4.00 & 0.0 & 495.0 & 55.0 & 44.3 & 1988.0 & 1823 & 0.92 \\
\hline & \multirow{5}{*}{ [16] } & 26 & S1 & 127.0 & 3.2 & 0.0 & 356.0 & 30.5 & 25.8 & 917.0 & 1024 & 1.12 \\
\hline & & 27 & S2 & 127.0 & 4.3 & 0.0 & 357.0 & 26.0 & 22.0 & 1095.0 & 1196 & 1.09 \\
\hline & & 28 & S3 & 127.0 & 4.6 & 0.0 & 322.0 & 23.8 & 20.2 & 1113.0 & 1117 & 1.00 \\
\hline & & 29 & S4 & 127.0 & 5.7 & 0.0 & 312.0 & 23.8 & 20.2 & 1202.0 & 1271 & 1.06 \\
\hline & & 30 & S5 & 127.0 & 7.5 & 0.0 & 347.0 & 23.8 & 20.2 & 2069.0 & 1699 & 0.82 \\
\hline & \multirow{2}{*}{ [17] } & 31 & 1.0 & 142.1 & 3.0 & 0.0 & 255.1 & & 43.7 & 1360.0 & 1309 & 0.96 \\
\hline & & 32 & 2.0 & 142.1 & 3.0 & 0.0 & 255.1 & & 43.7 & 1400.0 & 1309 & 0.94 \\
\hline
\end{tabular}




\begin{tabular}{|c|c|c|c|c|c|c|c|c|c|}
\hline 33 & 3.0 & 143.1 & 3.0 & 0.0 & 255.1 & 43.7 & 1150.0 & 1325 & 1.15 \\
\hline 34 & 4.0 & 101.3 & 5.0 & 0.0 & 347.3 & 48.1 & 1310.0 & 1177 & 0.90 \\
\hline 35 & 5.0 & 103.6 & 4.9 & 0.0 & 347.3 & 48.1 & 1340.0 & 1207 & 0.90 \\
\hline 36 & 6.0 & 102.0 & 5.0 & 0.0 & 347.3 & 48.1 & 1370.0 & 1189 & 0.87 \\
\hline 37 & 7.0 & 142.0 & 5.1 & 0.0 & 347.3 & 48.1 & 2160.0 & 1969 & 0.91 \\
\hline 38 & 8.0 & 142.0 & 5.1 & 0.0 & 347.3 & 48.1 & 2250.0 & 1963 & 0.87 \\
\hline 39 & 9.0 & 141.4 & 5.1 & 0.0 & 347.3 & 48.1 & 2280.0 & 1949 & 0.85 \\
\hline 40 & 10.0 & 141.5 & 3.1 & 0.0 & 255.1 & 60.8 & 1920.0 & 1621 & 0.84 \\
\hline 41 & 11.0 & 142.4 & 3.1 & 0.0 & 255.1 & 60.8 & 2060.0 & 1635 & 0.79 \\
\hline 42 & 12.0 & 141.6 & 3.0 & 0.0 & 255.1 & 60.8 & 1960.0 & 1618 & 0.83 \\
\hline 43 & 13.0 & 103.5 & 5.0 & 0.0 & 347.3 & 60.8 & 1500.0 & 1331 & 0.89 \\
\hline 44 & 14.0 & 102.1 & 5.0 & 0.0 & 347.3 & 60.8 & 1330.0 & 1299 & 0.98 \\
\hline 45 & 15.0 & 101.9 & 5.0 & 0.0 & 347.3 & 60.8 & 1440.0 & 1303 & 0.90 \\
\hline 46 & 16.0 & 142.3 & 5.1 & 0.0 & 347.3 & 60.8 & 2520.0 & 2193 & 0.87 \\
\hline 47 & 17.0 & 142.4 & 5.1 & 0.0 & 347.3 & 60.8 & 2610.0 & 2197 & 0.84 \\
\hline
\end{tabular}

\section{Unified formulation of stability bearing capacity for circle and polygonal long CFST columns}

\subsection{Modified formula of stability factor of circle section}

The above approach for developing the unified strength formula also applies to the formulation of stability factor of long CFST columns. By considering a concrete-filled steel tube column as a column made of a composite material, the stability factor has been obtained from Perry-Robertson formula in reference [1]. The fundamental assumption is that the equivalent initial imperfection coefficient is directly proportional to the steel ratio $\beta$, and the stability factor of a circular section ${ }^{[1]}$ is,

$$
\varphi_{s c}=\frac{1}{2 \bar{\lambda}_{s c}^{2}}\left[\bar{\lambda}_{s c}^{2}+K_{c} \bar{\lambda}_{s c}+1-\sqrt{\left(\bar{\lambda}_{s c}^{2}+K_{c} \bar{\lambda}_{s c}+1\right)^{2}-4 \bar{\lambda}_{s c}^{2}}\right]
$$

where, $\bar{\lambda}_{s c}$ is the non-dimensional slenderness ratio, $K_{c}$ is the initial imperfection coefficient of the circular CFST column. In reference [1], it was assumed that $K_{c}=0.25 \beta$.

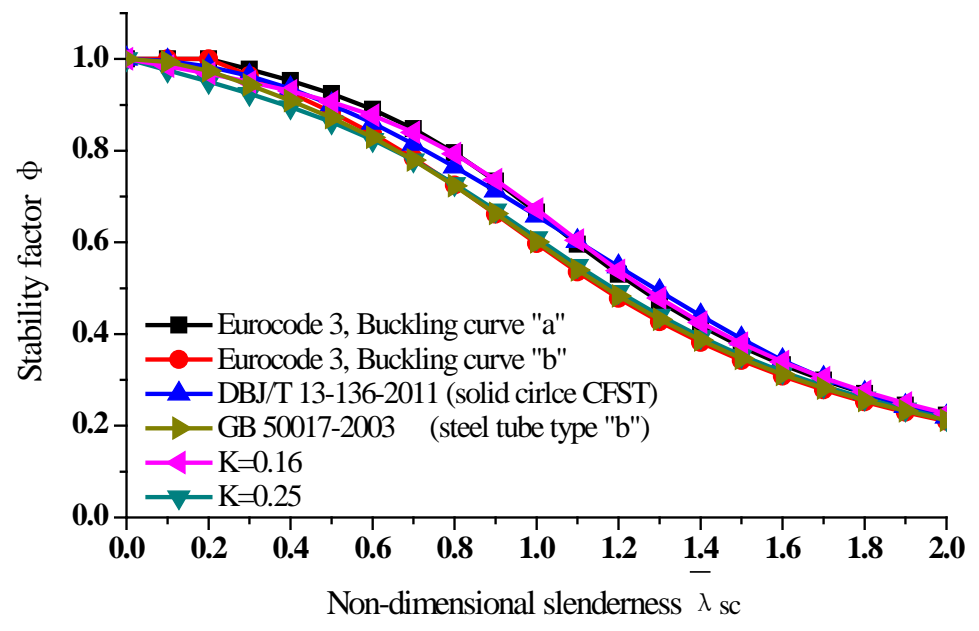

Figure 3-1 the stability factor vs. the non-dimensional slenderness

Figure 3-1 presents the stability factor curves against the non-dimensional slenderness from various design codes and formula Eq.(3-1). It can be seen from the figure that when $K_{c}=0.16$, the stability factor curve from Eq.(3-1) agrees well with the buckling curve "a” of Eurocode 3 and the buckling curve for solid 
CFST columns from the technical specification DBJ/T13-136-2011. It is found also that when $K_{c}=0.25$, the predicted stability factor curve agrees well with the buckling curve "b" of Eurocode 3 and the buckling curve of GB50017-2003 for steel tubes. Therefore, the value of the equivalent initial imperfection coefficient $\left(K_{c}\right)$ is calculated by linear interpolation of the hollow ratio $\left({ }^{\psi}\right)$ ranged from a circular hollow CFST $\left(K_{c}=0.16\right)$ to a steel tube $\left(K_{c}=0.25\right)$. Thus,

$$
K_{c}=0.16+0.09 \psi=0.25-0.09 \Omega=0.25-0.09 k_{h}
$$

\subsection{Extension of the stability factor to polygon sections}

By following the same procedure described in Section 3.1 for circular sections, The value of the imperfection coefficient for a polygonal section can be calculated by further assuming that the number of sides affects also the initial imperfection coefficient $K$. Thus, on the basis of Eq.(3-2), the following formula is proposed:

$$
K=0.25-0.09 k_{h} k_{n}=0.25-0.09 k_{e}
$$

where, $k_{e}$ is the confinement effectiveness coefficient.

When $n$ approaches infinity (circular CFST), the formula is reduced to the stability factor of a circular CFST column. When $\Omega=0$ (steel tube only), $K=0.25$, which is the value recommended by GB50017-2003.

From the above analysis, the unified formulation for predicting axial load bearing capacity of long circular and polygonal CFST columns are as follow:

$$
\begin{gathered}
N_{u}=\varphi_{s c} N_{0} \\
\varphi_{s c}=\frac{1}{2 \bar{\lambda}_{s c}^{2}}\left[\bar{\lambda}_{s c}^{2}+K \bar{\lambda}_{s c}+1-\sqrt{\left(\bar{\lambda}_{s c}^{2}+K \bar{\lambda}_{s c}+1\right)^{2}-4 \bar{\lambda}_{s c}^{2}}\right]
\end{gathered}
$$

where:

$N_{0}$ _ strength bearing capacity of CFST, using Eq.(2-18b);

$\varphi_{\mathrm{cr}} \longrightarrow$ stability factor of CFST;

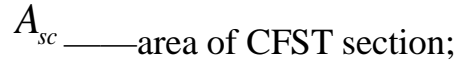

$\bar{\lambda}_{s c} \longrightarrow$ non-dimensional slenderness ratio, $\bar{\lambda}_{s c}=L_{0} / \pi \sqrt{N_{0} /\left(E_{s c} I_{s c}\right)}$;

$K$ __ initial imperfection coefficient, using Eq.(3-3).

\subsection{Verification of the stability load bearing capacity formula for uniaxial compression}

For circular CFST columns, this was done by recalculating the load bearing capacity of the long columns tested in Table 3 of reference [1] using Eq.(3-4) and comparing the predicted results with the test ones. It was found that the average ratio of $N_{c} / N_{\text {test }}$ was 0.912 , and the variance was 0.008 . The comparison shows that the simplified formula is still sufficiently accurate. In order to validate the application of the unified formula for polygonal CFST columns, available experimental results from Zhong ${ }^{[2]}$, Cao, et al ${ }^{[13]}$ and Guo, et al ${ }^{[18]}$ were compared with the predictions from Eq.(3-4) in Figure 3-1. Since available tests results on long columns are very limited, the finite element (FE) results of octagonal CFST columns due to She ${ }^{[29]}$ were also used in the validation shown in Fig.3-1. The comparisons show that the average ratio of the predicted load bearing capacity from the simple formula (3-4) and the results from other researchers is 0.956 and the variance is 0.008 for octagonal CFSTs. The average ratio is 1.024 and the variance is 0.008 for square solid CFST. From the 
comparisons, it can be seen that the unified formula and the experimental results agree reasonably well.

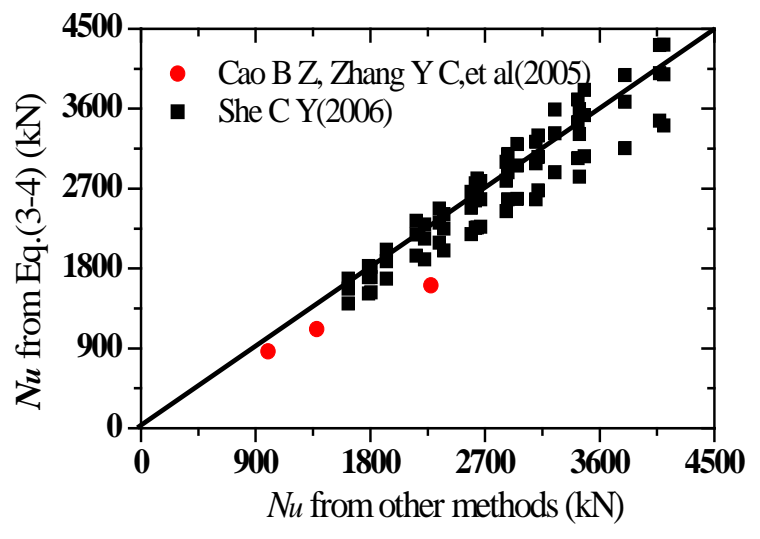

a) Octagonal hollow and CFST

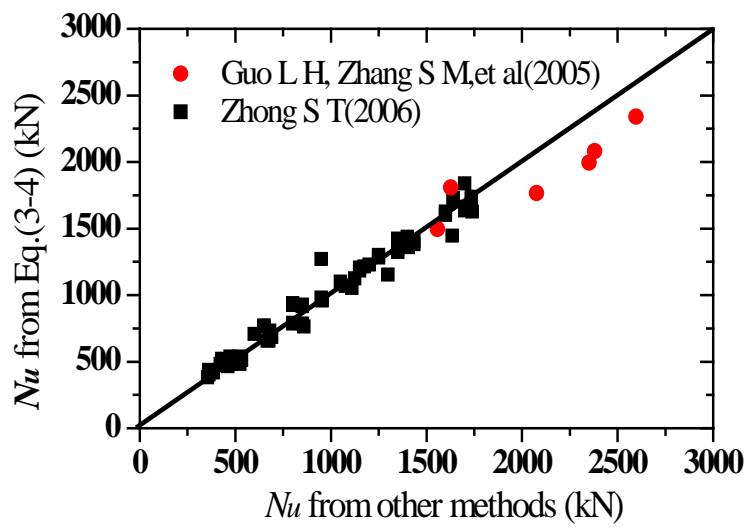

b) square solid CFST

Figure 3-1 Comparisons of the analytical, the test and the FEA results for long and short CFSTs

\section{Experimental study and verification of the bearing capacity of hollow CFSTs}

\subsection{Test specimen and procedure of long CFST columns under axial compression}

Extensive experimental study on the load bearing capacity of both short and long solid CFSTs has been carried out and well reported in the literature. However, reported experimental studies on hollow CFST long columns, especially square hollow CFSTs are very limited. The purpose of this section is to set up the test procedure for long, hollow CFST columns with circular and square sections. These test results are new and can be used in the future to validate new numerical models. In this paper, the test results are also used to further validate the applicability of the formulas that were derived independently in the previous sections.

In total, 6 circular and 6 square hollow-CFST long columns under axial compression were tested. The circular steel tube has a diameter $(D)$ of $219 \mathrm{~mm}$ and a thickness $(t)$ of $3.8 \mathrm{~mm}$. The length of the side of the square tube (B) was $200 \mathrm{~mm}$ and the thickness $(t)$ was $3.9 \mathrm{~mm}$. The hollow ratio of the columns ranged from 0.25 to 0.65 . The overall length of the columns was $3810 \mathrm{~mm}$, including the thickness of the two end plates, $20 \mathrm{~mm}$ each, attached to the ends of the columns.

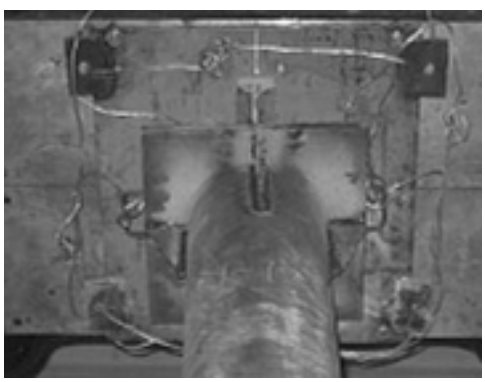

the top end

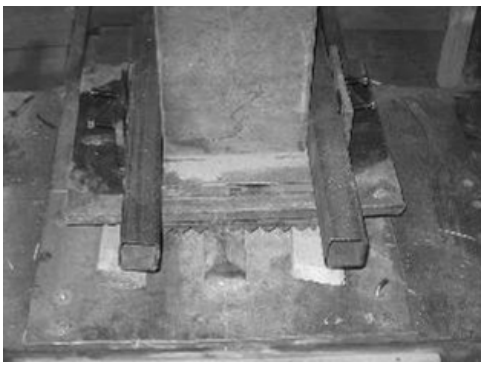

the bottom end
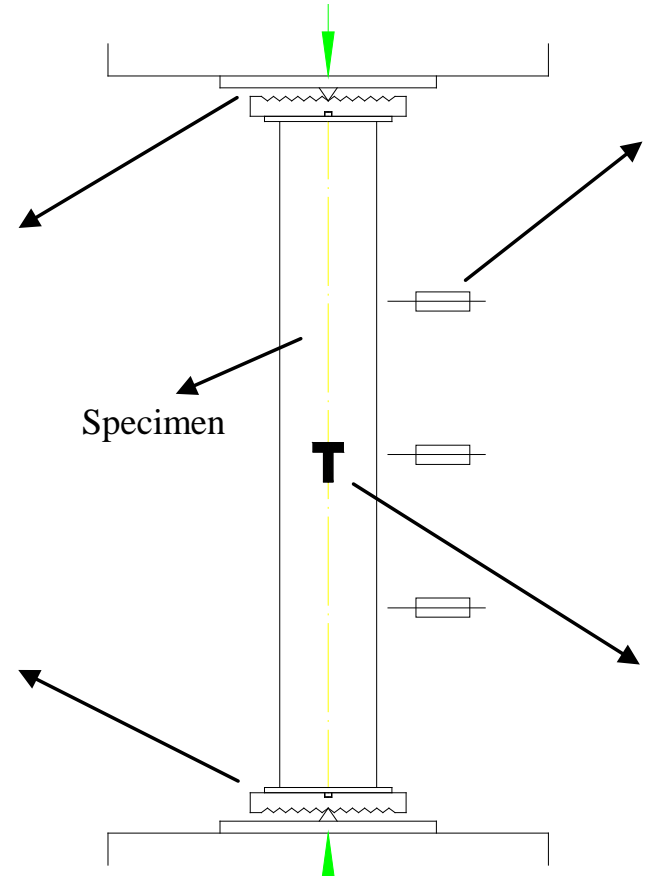

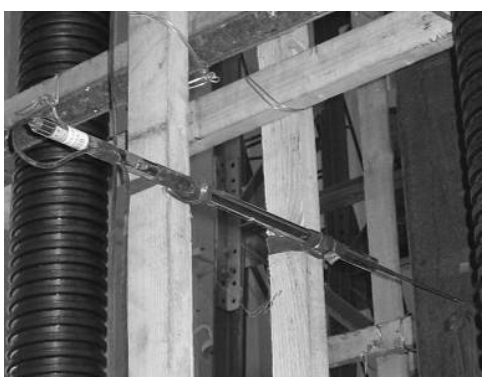

LVDT

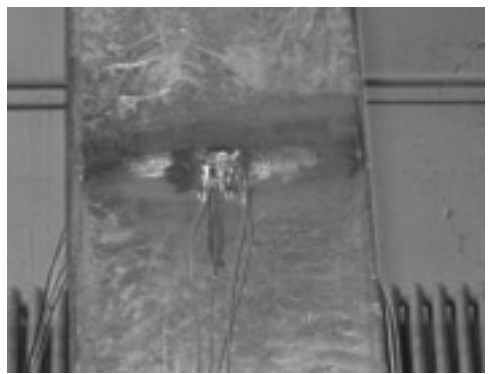

Strain Gauges 
Figure 3-2 Arrangement of tests

The test set-up is shown in Figure 3-2. Three LVDTs were used to measure the transverse deflection of the columns, of which one was for measuring the displacement at the mid span while the remaining two were mounted at a distance of L/3 from the two ends, respectively. Additionally, eight strain gauge rosettes, four on one side and the other four on the opposite side, were placed symmetrically at a vertical distance of L/2 from the top to measure the strains in the steel at these locations. The top and bottom ends of the column were connected to the supports allowing only the rotational displacements of the ends. The axial load was applied through a loading cell that has a maximum load capacity of 500ton.

\subsection{Experimental results and discussion}

Before the columns were tested, six concrete cubes of (100mmx100mmx100mm) were tested to measure their compressive strength. It was found that average 100mm cube compressive strength was 56.14Mpa, which was converted to a standard $150 \mathrm{~mm}$ cube compressive strength (fcu) of 53.3MPa. The standard compressive strength (fck) is 34.4Mpa, therefore, according to the Chinese Standard GB50010-2010. To determine the steel material properties, three tension coupons were cut from the square and circle steel tubes and tested. From these tests, the average yield strength (fy) of the circular tubes was $291.5 \mathrm{MPa}$, and the average yield strength (fy) of the square tubes was $322.8 \mathrm{Mpa}$.

The load -mid span deflection curves recorded from the tests are shown in Figure 3-3, and the deformation and failure modes of the hollow CFST columns are shown in Figure 3-4.

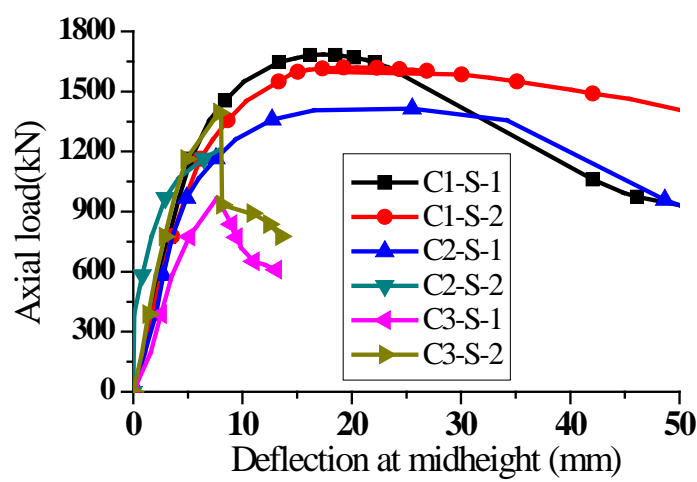

a) Circular hollow CFST

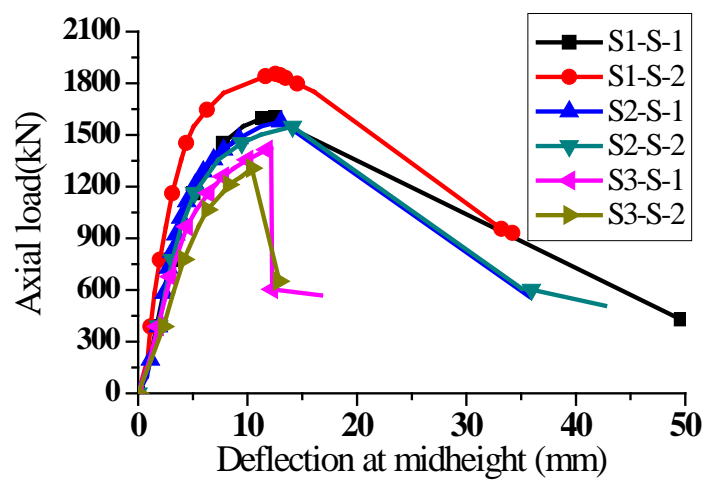

b) Square hollow CFST

Figure 3-3 Axial load - Midspan displacement curves of tests.

Detailed information and failure modes of the tested columns and the comparisons between the predicted and tested axial load capacity are presented in Table 3.1. Two major types of failure modes were observed in the tests: one is global buckling as shown in Figure 3-4a-b, and the other is end crushing shown in Figure 3-4c-d. For the circular hollow CFST columns, C1-S-1, C1-S-2 and C2-S-1, the dominating failure mode was global buckling and for C2-S-1, C3-S-1 and C3-S-2, the failure was caused by end crushing. For the square hollow CFST columns, S1-S-1, S1-S-2, S2-S-1 and S2-S-2 failed due to global buckling, while for S3-S-1 and S3-S-2, crushing occurred at the ends of the columns.

During the tests, it was observed that the radius of hollow had significant effect on the failure modes. In general, when the thickness of concrete is small, the column end tends to crush suddenly. For the columns failed from global buckling, it can be seen from Figure 3-3 that the circular hollow CFST columns show more ductility in comparison with the square ones. From Table 3.1, it is noticed that as the hollow ratio increases, the failure modes tend to change from global bucking to end crashing for both circular and square columns. Thus, special consideration should be taken in designing the hollow sections, since any brittle failure, such as the end crash of the columns, must be avoided. Additional reinforcement or strengthening at the end may be considered in design. 


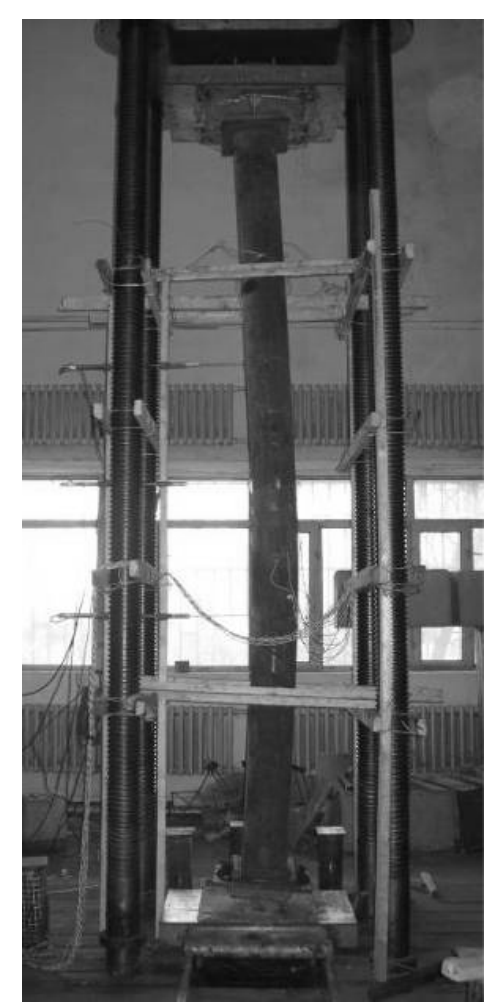

a) C2-S-1

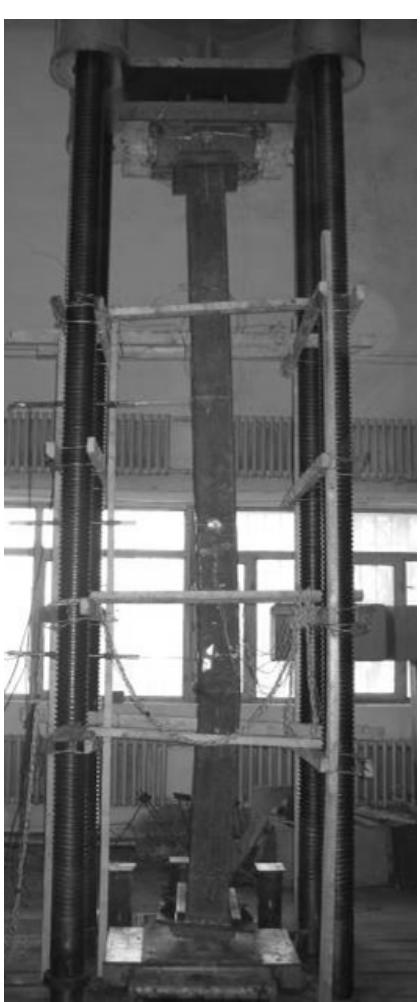

b) S2-S-2

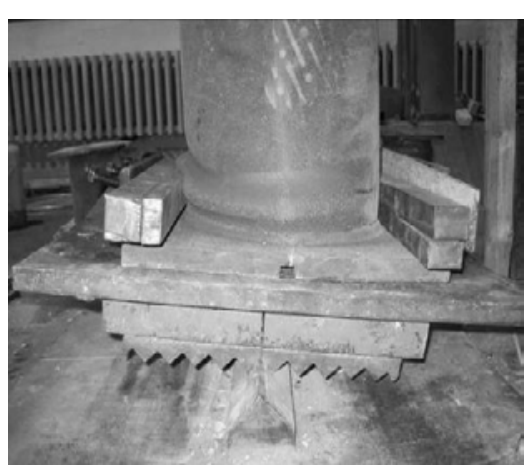

c) C3-S-1

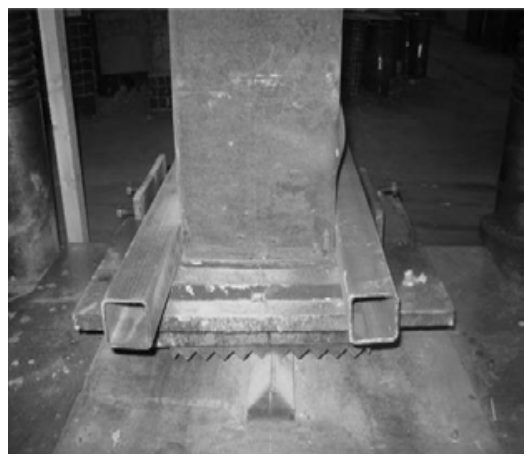

d) S3-S-2

Figure 3-4 Failure modes of columns

It has to be mentioned that the unified formulas proposed in this paper considered only the strength of short columns and global buckling of long columns. Predictions to the failure due to the observed end crush were not included. This is demonstrated by the good agreement between the tested and the predicted axial load bearing capacity of the columns failed due to global buckling. However, the comparisons show also good agreement for most of the columns failed due to end crash. This may be because the crashed ends created additions joints near the two ends, which perhaps only weakened slightly the pined end supports and this did not affect the overall axial load bearing capacity significantly.

Table 3-1 Test results and calculation result of 12 long columns

\begin{tabular}{|c|c|c|c|c|c|c|c|c|c|c|}
\hline \multirow{3}{*}{ Shape } & \multirow{3}{*}{$\begin{array}{l}\text { Specimen } \\
\text { Number }\end{array}$} & \multicolumn{4}{|c|}{ Geometric parameters } & \multicolumn{2}{|c|}{ Material } & \multirow{3}{*}{$\begin{array}{c}\text { Tests } \\
\text { Ntest } \\
\text { /KN }\end{array}$} & \multirow{3}{*}{$\begin{array}{l}\text { Cal. } \\
\\
\text { Nc } \\
/ \mathrm{kN}\end{array}$} & \multirow{3}{*}{$\begin{array}{l}\text { Fail } \\
\text { mode }\end{array}$} \\
\hline & & $\begin{array}{l}\text { Dimension or } \\
\text { length of side }\end{array}$ & $\begin{array}{c}\text { Steel } \\
\text { Thickness }\end{array}$ & $\begin{array}{l}\text { Radius } \\
\text { of hollow }\end{array}$ & length & \multirow[t]{2}{*}{ fy/MPa } & \multirow[t]{2}{*}{ fck/MPa } & & & \\
\hline & & $\mathrm{D}$ or $\mathrm{B} / \mathrm{mm}$ & $\mathrm{t} / \mathrm{mm}$ & $\mathrm{rco} / \mathrm{mm}$ & $\mathrm{L} / \mathrm{mm}$ & & & & & \\
\hline \multirow{6}{*}{$\begin{array}{l}\text { Circular } \\
\text { Hollow } \\
\text { CFST }\end{array}$} & C1-S-1 & 219 & 3.8 & 51.8 & 3810 & 291.5 & 34.4 & 1684 & 1629 & \multirow{3}{*}{$\begin{array}{c}\text { Global } \\
\text { buckling }\end{array}$} \\
\hline & C1-S-2 & 219 & 3.8 & 50.5 & 3810 & 291.5 & 34.4 & 1619 & 1644 & \\
\hline & C2-S-1 & 219 & 3.8 & 61.3 & 3810 & 291.5 & 34.4 & 1414 & 1504 & \\
\hline & C2-S-2 & 219 & 3.8 & 64.8 & 3810 & 291.5 & 34.4 & 1210 & 1452 & \multirow{3}{*}{$\begin{array}{l}\text { End } \\
\text { crush }\end{array}$} \\
\hline & C3-S-1 & 219 & 3.8 & 80.3 & 3810 & 291.5 & 34.4 & 969 & 1185 & \\
\hline & C3-S-2 & 219 & 3.8 & 82.0 & 3810 & 291.5 & 34.4 & 1394 & 1153 & \\
\hline
\end{tabular}




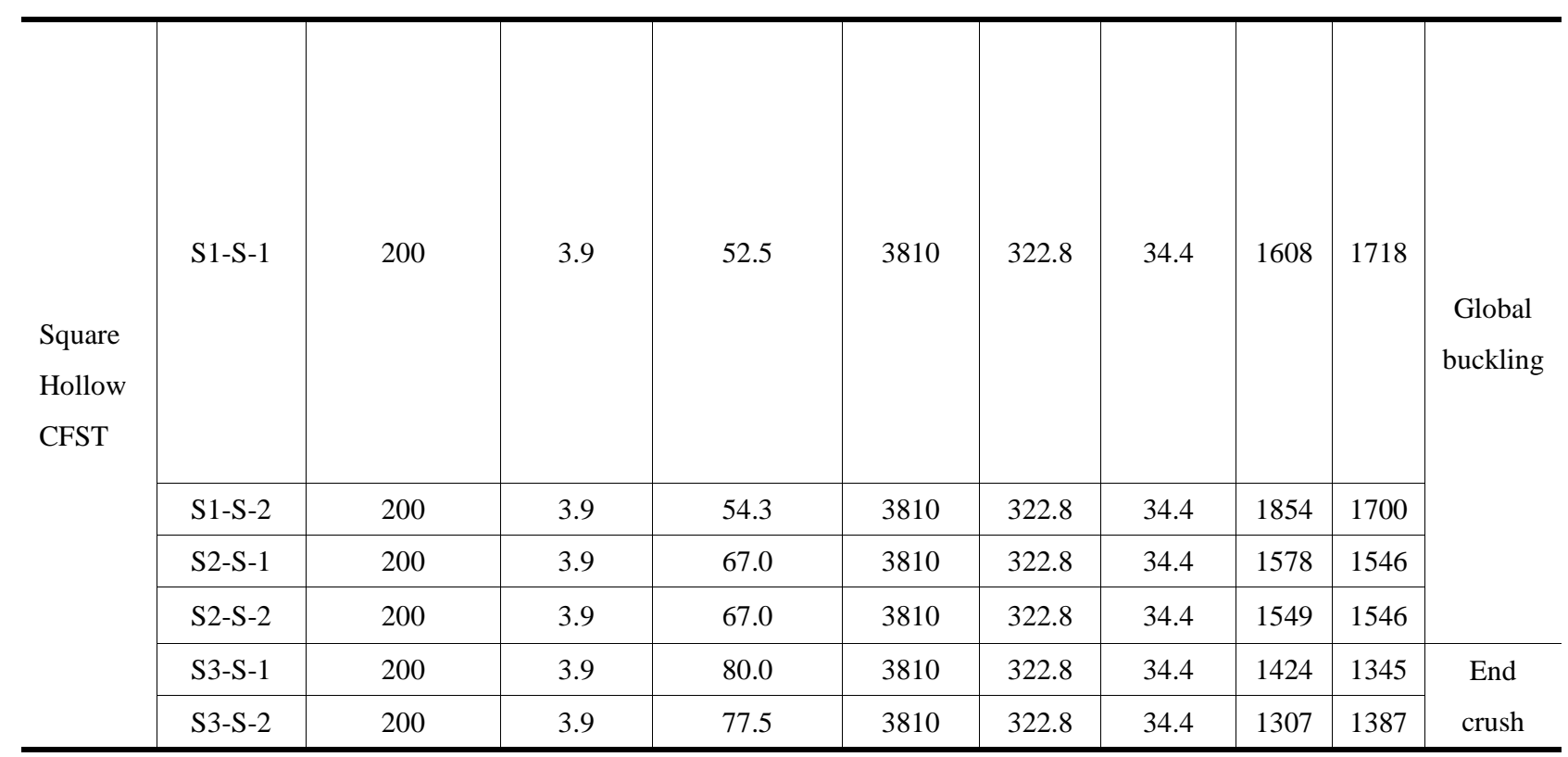

In Table 3-1, the average ratio of $N_{c} / N_{\text {test }}$ is 1.050 and the variance is 0.018 for the circular hollow columns, and these are respectively 0.995 and 0.003 for the square hollow ones.

\section{Summary of the unified formation for circle and polygon CFST column under axial}

\section{load}

Since a rather large number of equations or formulas have been presented in the previous sections, and not all of them are required in a typical design calculation, this section summarizes the most important formulas and the key steps that should be followed in the calculation of axial load bearing capacity of solid, hollow, circle and polygonal concrete-filled steel tube columns under axial compression:

Step 1: Calculate strength capacity of a CFST section by:

$$
N_{0}=(1+\eta)\left(f_{y} A_{s}+f_{c k} A_{c}\right)
$$

where, $\quad \eta$ - enhanced confining coefficient, $\eta=0.5 k_{e} \frac{\xi}{1+\xi}$;

$\xi-$ confining coefficient, $\xi=A_{s} f_{y} / A_{c} f_{c k}$;

$k_{e}$ - confinement effectiveness coefficient, $\quad k_{e}=(1-\psi)\left(n^{2}-4\right) /\left(n^{2}+20\right)$.

Step 2: Calculate the stability factor by

$$
\varphi_{s c}=\frac{1}{2 \bar{\lambda}_{s c}{ }^{2}}\left[\bar{\lambda}_{s c}{ }^{2}+K \bar{\lambda}_{s c}+1-\sqrt{\left(\bar{\lambda}_{s c}{ }^{2}+K \bar{\lambda}_{s c}+1\right)^{2}-4 \bar{\lambda}_{s c}{ }^{2}}\right]
$$

where, $\bar{\lambda}_{s c}$ — normalized slenderness ratio $\bar{\lambda}_{s c}=\frac{L_{0}}{\pi} \sqrt{\frac{N_{0}}{E_{s c} I_{s c}}}$;

$K$ - initial imperfection coefficient, $K=0.25-0.09 k_{e}$;

$E_{s c} I_{s c}$ —— the composite bending rigidity, $E_{s c} I_{s c}=E_{c} I_{c}+E_{s} I_{s}$.

Step 3: Calculate the stability load bearing capacity by 


$$
N_{u}=\varphi_{s c} N_{0}
$$

\section{Concluding remarks}

A unified formulation for predicting load bearing capacity of both circular and polygonal CFST columns has been proposed in the paper. This was based on the simplified form of the strength formula for circular CFST columns proposed in the authors' previous study [1] and the extension of the formulas to columns with polygonal sections.

A modified formula of the stability factor for circular CFST column was also proposed. The linear interpolation technique was used to estimate the stability coefficient for columns with different hollow ratios. The factor was then introduced into the unified formula to calculate the stability load bearing capacity of both circular and polygonal CFST columns.

The proposed unified formulas were validated through comparisons with available test results and the new test results of circular and square hollow CFST long columns under axial load reported also in this paper. The comparisons showed satisfactory agreement and suggested that the simplified unified formulas had potential to be used in practical design.

Future work is needed to extend the load bearing capacity formulas of CFST columns to include the effect of temperature elevation.

\section{References}

[1] Yu M, Zha XX, Ye JQ. et al. A Unified Formulation for Hollow and Solid Concrete-Filled Steel Tube Columns under Axial Compression [J]. Engineering structures. 2010, 32(4):1046 1053.

[2] Zhong ST. Research and Application Achievement of Concrete-Filled Steel Tubular (CFST) Structures [M]. Beijing: Tsinghua University Press, China; 2006. (in Chinese)

[3] Han LH. Concrete filled steel tubular structures from theory to practice [M]. Beijing: Science Press, 2007. (in Chinese)

[4] Zhao XL, Han LH, Lu H. Concrete-Filled Tubular Members and Connections. Taylor \& Francis, 2010.

[5] Zha XX. Hollow and solid concrete-filled steel tube structures[M]. Beijing: Science Press, 2010. (in Chinese)

[6] Matsui Chiaki. Performance and design of concrete-filled steel tubular structure. Ohmsha, 2009.

[7] Han LH, He SH and Liao FY. Performance and calculations of concrete filled steel tubes (CFST) under axial tension [J]. Journal of Constructional Steel Research. 2011, 67(11): 1699-1709.

[8] Wang YC. Tests on Slender Composite Columns[J]. Journal of Constructional Steel Research. 1999, 64(11):1275-1282.

[9] Yu Z W, Ding F X, Cai C S. Experimental Behavior of Circular Concrete-Filled Steel Tube Stub Columns [J]. Journal of Constructional Steel Research, 2007,63(2):165-174.

[10] Yang H, Lam D and Gardner L. Testing and analysis of concrete-filled elliptical hollow sections [J]. Engineering Structures. 2008, 30(2): 3771-3781.

[11] Zhang YC, Wang QP, Mao XY and Cao BZ. Research on Mechanics Behavior of Stub -column of Concrete-filled Thin -walled Steel Tube under Axial Load[J]. Building Structure , 2005,35(1):22-27. (in Chinese)

[12] Tomii M, Yoshimura K, Morishita. Y. Experimental Studies On Concrete-Filled Steel Tubular Stub Columns under Concentric Loading[C]//International Colloquium on Stability of Structures under Static and Dynamic Loads, Washington DC, May 17-19, 1977:718-741.

[13] Cao BZ, Zhang YC, Zhao YM. Experimental Research On Concrete Filled Thin-Walled Steel Tube Long Columns[J]. Key Engineering Materials, 2009,400-402:551-557. 
[14] Liu DL. Tests On High-Strength Rectangular Concrete-Filled Steel Hollow Section Stub Columns[J]. Journal of Constructional Steel Research, 2005, 61(7):902-911.

[15] Liu DL, Gho WM. Axial Load Behaviour of High-Strength Rectangular Concrete-Filled steel Tubular Stub Columns[J]. Thin-Walled Structures, 2005, 43(8):1131-1142.

[16] Schneider SP. Axially Loaded Concrete-Filled Steel Tubes[J]. Journal of Structural Engineering, 1998, 124(10):1125-1138.

[17] Zhang SM, Guo LH, Ye ZL, et al. Behavior of Steel Tube and Confined High Strength Concrete for Concrete-Filled RHS Tubes[J]. Advances in Structural Engineering, 2005, 8(2):101-116.

[18] Guo LH, Zhang SM, Wang YY, et al. Experimental And Analytical Research On Axially Loaded Slender High Strength Concrete-Filled RHS Tubes[J]. Industrial Construction, 2005,35(3):75-79.(in Chinese)

[19] Ellobody E and Young B. Nonlinear analysis of concrete-filled steel SHS and RHS columns [J]. Thin-Walled Structures. 2006, 44(8): 919-930.

[20] Hu HT, Huang CS, Wu MH. et al. Nonlinear Analysis of Axially Loaded Concrete-Filled Tube Columns with Confinement Effect [J]. Journal of Structural Engineering. 2003, 129(10):1322 1329.

[21] Tao Z, Uy B, Liao FY and Han LH. Nonlinear analysis of concrete-filled square stainless steel stub columns under axial compression [J]. Journal of Constructional Steel Research. 2011, 67(11): 1719-1732.

[22] Dai X and Lam D. Numerical Modelling of the Axial Compressive Behaviour of Short Concrete-Filled Elliptical Steel Columns [J]. Journal of Constructional Steel Research. 2010, 66(4):542 555.

[23] Portolés, JM, Romero ML, Filippou FC and Bonet JL. Simulation and design recommendations of eccentrically loaded slender concrete-filled tubular columns[J]. Engineering Structures, 2011, 33(5): 1576-1593.

[24] Liang QQ and Fragomeni S. Nonlinear analysis of circular concrete-filled steel tubular short columns under eccentric loading [J]. Journal of Constructional Steel Research. 2010, 66(2):159-169.

[25] CECS 254:2009. Technical specification of hollow concrete-filled steel tubular structures [S]. China association for engineering construction standardization, 2009. (in Chinese)

[26] Eurocode 4. BS EN 1994-1-1:2004. Design of composite steel and concrete structures. Part 1-1: General rules and rules for buildings[S]. British Standards Institution, 2004.

[27] Varma AH, Sause R, Ricles JM. et al. Development and Validation of Fiber Model for High-Strength Square Concrete-Filled Steel Tube Beam-Columns [J]. ACI structural journal. 2005, 102(1):73 84.

[28] Mander JB, Priestley M. and Park R. Theoretical Stress-Strain Model for Confined Concrete [J]. Journal of Structural Engineering. 1988, 114(8):1804 1826.

[29] She CY. Research on the Strength and Stability of Hollow Polygonal Concrete-Filled Steel Tubes [D]. Harbin institute of Technology, 2008. (in Chinese) 